\title{
A Área de CONCENTRAÇÃo: Planejamento URbano E REGIONAL, NO CONTEXTO DA PÓS DA FAUUSP. SÍNTESE DO SEMINÁRIO REALIZADO EM I 8/6/2004
}

\author{
Wilson Edson Jorge \\ Nuno de Azevedo Fonseca
}

Este artigo é fruto do seminário da área de concentração de Planejamento Urbano e Regional, realizado em 18/6/2004, que abordou temas básicos relacionados à área e ao Programa de Pós-graduação da FAUUSP. Entre esses temas ganham destaque a questão da identidade da área de concentração, a necessidade de unidade ao conjunto de disciplinas oferecidas, com a definição de linhas de pesquisa e procedimentos de orientação; a continuidade das mudanças no programa de pós-graduação da FAUUSP diante do crescimento do programa; as novas exigências de desempenho colocadas por padrões de avaliação externa comuns a todas as áreas do conhecimento; e uma realidade no âmbito da pósgraduação diversa daquela do surgimento do programa. Para lembrarmos, o programa de mestrado foi iniciado em 1972, e o de doutorado em 1980, tendo sido o único no Brasil a oferecer o título de doutor até o ano de 1998.

A pós-graduação da FAU tem sua problemática vinculada no perfil que o curso foi assumindo ao longo de sua história. A integração entre as áreas de projeto - tanto os projetos de arquitetura como de design, programação visual e paisagismo - e a área de planejamento urbano e regional criou um perfil de curso no qual a crítica às formas de produção da arquitetura e da cidade leva a uma postura e atuação conscientes do arquiteto perante a dinâmica do Estado e do mercado. Ao mesmo tempo, o programa cresceu muito desde seu início e essa estrutura, abarcando hoje oito áreas de concentração e um número grande de orientadores (122), exige um grande esforço para sua organização, inclusive em sua adequação, em face dos critérios de avaliação institucional colocados pela Capes e outros órgãos financiadores.

A questão da avaliação pela Capes e da obtenção de financiamentos e bolsas permeou toda a discussão trazida pelo seminário, como um dos pontos críticos a serem equacionados, por exemplo, sobre a necessidade de alterar o perfil dos alunos de forma a que seja mais viável atingir os índices de excelência exigidos pela Capes, a necessidade de definir-se o que é pesquisa a partir dos critérios dos órgãos financiadores, de maneira que nossas pesquisas respondam a esses critérios, etc.

O seminário teve como ponto de partida a exposição, por parte de professores e alunos, de seus pontos de vista com relação aos temas básicos relacionados.

Em seguida, foi listada uma série de qualidades e problemas enfrentados por nosso programa de pós-graduação: 
Qualidades:

1. Porte, quantidade de orientandos que se formam anualmente - quase a totalidade dos doutores do Brasil, na área de arquitetura e urbanismo, são formados pela própria pós da FAUUSP.

2. Biblioteca, acervo, instalações.

3. Publicações

- Revista da pós

- Média de publicações por professor da pós:

• $2002-1,8$

-2003 - 3

- Existem outras revistas indexadas que aceitam nossos trabalhos;

- Recomendações para o tema:

- retomar contatos com revistas da área para publicação da produção da pós;

- incentivar publicação de alunos;

- projeto, em determinados casos, pode ser considerado trabalho de pesquisa e publicado.

Problemas estruturais na pós-graduação:

1. Pesquisa: não há entendimento claro por parte dos professores e coordenadores das áreas de concentração quanto ao significado dessas áreas dentro do programa, tampouco quanto à vinculação entre elas e o desenvolvimento de pesquisas ou a formação de grupos de pesquisa institucional. Isso tem como conseqüência um número elevado de linhas e projetos de pesquisa individuais e sem financiamento que, associado ao baixo índice de publicações, prejudica a avaliação do programa nos quesitos de atividades de pesquisa e de produção intelectual.

2. Publicações do corpo docente: critério Capes - 4 a 5, por ano, por professor.

3. Falta de informação sobre a produção dos docentes: somente $50 \%$ dos docentes disponibilizou seu curriculum lattes para a montagem do relatório Capes.

A estruturação da ACPUR foi feita levando em consideração os órgãos de financiamento e avaliação. Assim, a escolha do nome da área foi uma decisão relativa a uma identidade amadurecida historicamente. Planejamento Urbano e Regional já é um setor classificado oficialmente nos órgãos de financiamento.

A área foi formada por professores com disciplinas na pós-graduação relacionadas aos estudos regionais e urbanos, em um âmbito mais amplo que o planejamento. No entanto, essa estruturação inicial não garante, per se, a unidade da área. Ainda subsistem questões que precisam ser enfrentadas e resolvidas:

- Quais as linhas de investigação que a área tem?

- O que é pesquisa (pela definição dos órgãos de financiamento, pesquisa é aquilo que é financiado, desenvolvida por uma equipe, inclusive com bolsas).

- As disciplinas correspondem a pesquisas em andamento, a processos de orientação?

- O que são processos de orientação e como se dão?

- Como dar unidade à área de concentração?

-É necessária uma unidade da área de concentração com a definição de questões básicas a serem abordadas em suas pesquisas?

- Quais as novas questões que estão surgindo no âmbito da área de concentração? Elas exigiriam uma postura investigativa por parte da área? 
A importância da avaliação do programa pela Capes, além de uma integração institucional e científica com os demais programas, está na obtenção de verbas para as pesquisas em desenvolvimento, e também para bolsas aos alunos. Atualmente, temos uma avaliação com nota 5 (em um gradiente de 3 a 7). Programas com avaliação entre 6 e 7 são considerados de excelência.

A obtenção de uma avaliação melhor, que merecemos, está ligada a uma série de exigências, algumas relativamente menos problemáticas, dizem respeito a questões de informação dos docentes quanto a orientações na graduação ou à entrega do curriculum lattes por parte dos mesmos. Outras dizem respeito à produção e inserção internacional, publicações por parte do corpo docente (segundo os critérios da Capes - o ideal seria uma média de 4 a 5 publicações ao ano, por docente), especialmente em periódicos internacionais, cursos ou convênios entre universidades de países diferentes, etc.; existência de pesquisas reconhecidas pelos critérios oficiais (existência de financiamento, existência de equipes, bolsas, etc.); e ao enquadramento do programa aos padrões da Capes no que diz respeito, por exemplo, aos prazos para conclusão dos programas de mestrado e doutorado por parte dos alunos. Segundo os padrões da Capes, esses prazos deveriam ser de 2 anos para o mestrado e 3 anos para o doutorado. Os prazos máximos fixados pela pós da FAUUSP são de 3 anos para o mestrado e 4 para o doutorado - um ano a mais para cada um dos programas com relação aos prazos da Capes, com a agravante que boa parte de nossos alunos $(67 \%$ dos que deveriam ter concluído em 2002 e $45 \%$ dos quais deveriam ter concluído em 2003) não conclui os programas dentro dos prazos máximos estipulados, recorrendo a prorrogações e trancamentos.

Em função das questões relativas às exigências da Capes, houve uma série de intervenções durante o seminário sobre qual o rumo a ser tomado para o cumprimento das mesmas.

Algumas intervenções foram no sentido que precisamos fazer chegar à Capes as especificidades de nosso programa, de forma a adequar os critérios de avaliação que não consideram, injustamente, aquela realidade. Embora não descartada essa hipótese, mostra-se necessário distinguir quais são os procedimentos e indicadores que estão superados ou são inadequados - o que deve ser revisto por uma questão de convicção acadêmica e de desempenho acadêmico -, daqueles cuja revisão possa ser secundária, em função de uma condição passageira do programa.

Outras colocações focaram o perfil do aluno que temos e o perfil de aluno que desejamos ter na pós-graduação da FAUUSP. O atual perfil dos primeiros, que tradicionalmente recebemos, é serem oriundos de órgãos públicos, docentes em outras instituições de ensino ou ainda profissionais atuantes no mercado. Esse perfil torna difícil resolver questões como a redução dos prazos para conclusão das dissertações e teses.

À sugestão que houvesse um esforço no sentido de alterar-se o perfil dos alunos, surgiram várias objeções, salientando-se, em primeiro lugar, que o papel cumprido de formação dos quadros profissionais os quais, tradicionalmente, demandam o programa, é de extrema importância, não devendo ser abandonado; além disso, se houvesse essa tentativa, o programa correria o risco de ficar bastante reduzido, por força da eliminação de grande parte dos candidatos que, normalmente, demandam o programa. 
Outra posição em face dessa questão foi: devemos preocupar-nos em estabelecer condutas acadêmicas e de pesquisa sistematicamente ao longo do programa, e que estas exigências acabarão por levar a um novo perfil do aluno. A própria definição de padrões de orientação e exigências diante das pesquisas acabaria por selecionar os candidatos e a definir um perfil de aluno adequado a essas exigências.

Assim, a diferença no produto final será mais conseqüência do estabelecimento de condutas acadêmicas e de pesquisa, ao longo do programa, do que uma tentativa de selecionar um determinado perfil de aluno. Essas condutas apontam para:

- Identidade da área de concentração e necessidade de coerência e temática do conjunto de disciplinas oferecidas, perante as linhas de pesquisa da área e procedimentos de orientação sistemáticos;

- a continuidade das mudanças no Programa de Pós-graduação da FAUUSP diante de seu próprio crescimento;

- as novas exigências de desempenho colocadas por padrões de avaliação externa comuns a todas as áreas do conhecimento;

- o reconhecimento e postura coerente em face de uma realidade no âmbito da pós-graduação, diversa daquela quando do surgimento do programa.

As questões levantadas de identidade, unidade e definição de linhas de pesquisa da área de concentração e de adaptação aos padrões de avaliação externa colocam em pauta a discussão da definição do tipo de pós-graduação que interessa à FAUUSP. Ao longo do debate apareceram posições que, esquematicamente, podem ser descritas pelos seguintes modelos:

- Opção por um modelo no qual haja turmas de mestrado e doutorado que cursem, junto, algumas disciplinas e participem de atividades comuns. Seria uma opção por um modelo mais próximo a um curso de pós-graduação.

- Opção por um modelo semelhante ao anterior, com o acréscimo da existência de um mestrado profissionalizante, sendo o desempenho do aluno que o encaminharia para o tipo de mestrado mais adequado ao seu interesse.

- Opção pelo oferecimento de um curso de pós-graduação sem a necessidade de apresentação de uma dissertação ou tese, podendo o aluno, ao final deste curso inicial, optar pelo diploma correspondente ao mesmo, sem trabalho final ou optar pela realização de uma dissertação ou tese.

- Opção pelo oferecimento de uma série de disciplinas, que não necessariamente contenham uma unidade entre si, deixando ao aluno e orientador a opção pelas disciplinas e pelo encaminhamento da pesquisa. É uma hipótese que privilegia mais o trabalho individual.

Prof. Dr. Wilson Edson Jorge

Professor do curso de graduação e pós-graduação da FAUUSP.

Prof. Dr. Nuno de Azevedo Fonseca

Professor do curso de graduação e pós-graduação da FAUUSP. 